\title{
The Validity and Reliability between Automated Oscillometric Measurement of Ankle-Brachial Index and Standard Measurement by Eco-Doppler in Diabetic Patients with or without Diabetic Foot
}

\author{
Jing Ma, ${ }^{1}$ Min Liu, ${ }^{1}$ Dawei Chen, ${ }^{1}$ Chun Wang, ${ }^{1}$ Guanjian Liu, ${ }^{2}$ and Xingwu Ran ${ }^{1}$ \\ ${ }^{1}$ Diabetic Foot Care Center, Department of Endocrinology and Metabolism, West China Hospital, Sichuan University, \\ Chengdu 610041, China \\ ${ }^{2}$ Chinese Cochrane Center, Chinese EBM Center, West China Hospital, Sichuan University, Chengdu 610041, China
}

Correspondence should be addressed to Xingwu Ran; ranxingwu@163.com

Received 8 February 2017; Revised 11 March 2017; Accepted 26 March 2017; Published 9 May 2017

Academic Editor: Peng-Fei Shan

Copyright (c) 2017 Jing Ma et al. This is an open access article distributed under the Creative Commons Attribution License, which permits unrestricted use, distribution, and reproduction in any medium, provided the original work is properly cited.

\begin{abstract}
Objective. To evaluate the concordance between oscillometric ABI and standard Doppler ABI in diabetic Chinese patients with or without diabetic foot. Methods. 230 consecutive diabetic patients $(n=459$ limbs) were included. The right and left ABIs were determined with both devices by the same investigator. The concordance and agreement were assessed by kappa index and the Bland-Altman method. Results. The average Doppler ABI was $1.003 \pm 0.286$ on the right and $0.990 \pm 0.287$ on the left, while oscillometric ABI was $1.002 \pm 0.332$ and $0.993 \pm 0.319$, which had no significance. The average time for oscillometric ABI was 8.600 versus 16.980 minutes for Doppler ABI $(p<0.001)$. There was good agreement between the two measurements, with a kappa value of 0.869 on the right and 0.919 on the left. Regarding the Doppler ABI as the gold standard, the accuracy, sensitivity, specificity, +LR, and -LR of oscillometric ABI reached 95.22\%, 94.34\%, 95.48\%, $20.873 \%$, and $0.059 \%$ on the right. For the left, it was $96.94 \%, 96.43 \%, 97.11 \%, 33.364 \%$, and $0.036 \%$. Conclusions. The oscillometric measurement is a reliable, convenient, and less time-consuming alternative to standard Doppler ABI in patients. It should be widely used for PAD detection.
\end{abstract}

\section{Introduction}

Peripheral arterial disease (PAD) is a common manifestation of atherosclerosis in patients with diabetes in China [1]. The prevalence of PAD in patients with type 2 diabetes aged 50 years and older is $19.47 \% \sim 23.8 \%[2,3]$. PAD is significantly associated with an increased risk of cardiovascular morbidity and mortality $[4,5]$ and independently related with impaired lower extremity functioning [6]. Further, PAD patients with diabetes had a significantly increased risk for death within 10 years than did the PAD patients without diabetes [7]. However, most of PADs are asymptomatic; evidence suggests that there is currently a lack of awareness regarding PAD among physicians and patients, leading to underdiagnosis and undertreatment [8]. To reduce the cardiovascular morbidity and mortality, it is very important for early screening, diagnosis, and treatment of PAD. Measurement of the anklebrachial index $(\mathrm{ABI})$ is a simple and noninvasive method and generally recommended for middle-aged populations with elevated cardiovascular risk levels for the screening and diagnosing for PAD [9]. Eco-Doppler is considered the gold standard for ABI test; the cut-off values for PAD are 0.9 and 1.4 [10]. However, it requires a trained technician, it is time consuming, and it has a high intraobserver variability of 


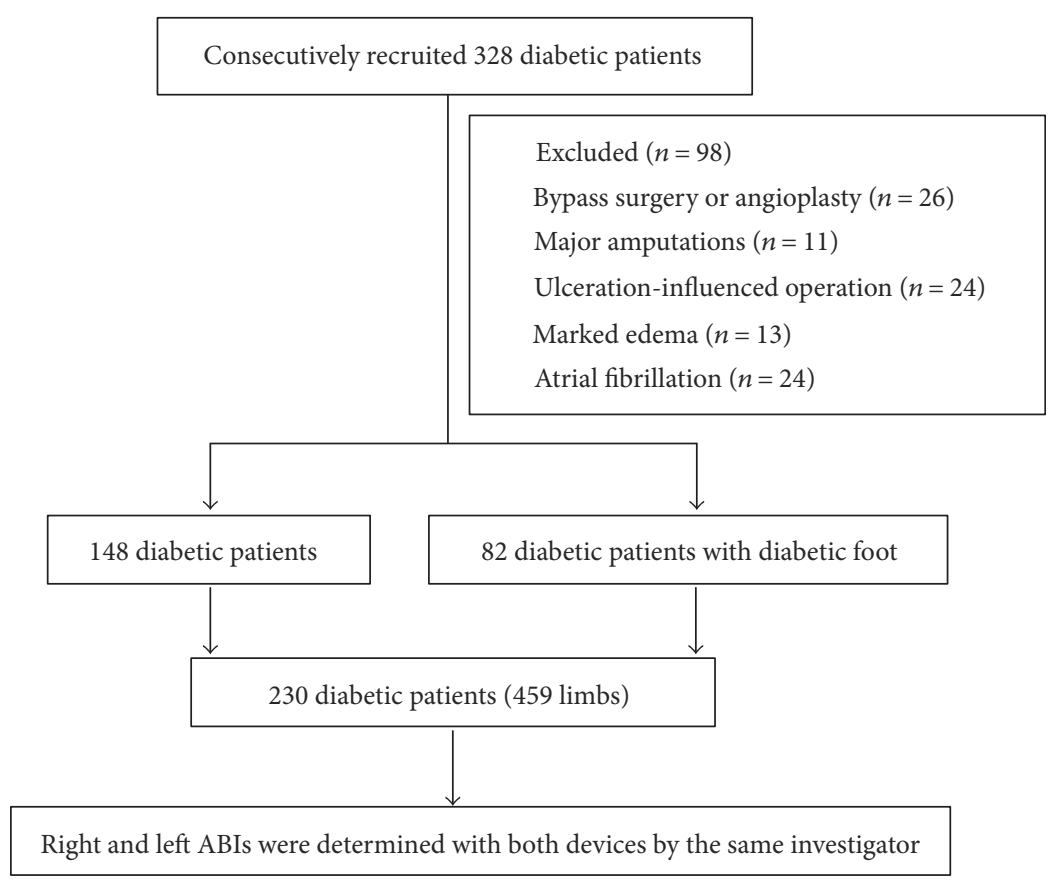

Figure 1: Flow chart of the study.

$10 \%$, which limited its routine use in clinical practice and did not seem suitable for the screening of PAD in primary care consultations [11].

To overcome such obstacles and simplify measurement procedures, automatic devices have been developed. Some recent studies have shown that the automated oscillometric method appears to be convenient and useful compared with eco-Doppler $[12,13]$. The oscillometric method can be suitable for screening of PAD in the community due to having a simple procedure, being easy to perform, and not requiring training [14-17]. But some studies showed that it cannot be recommended as a reliable method for ABI measurement and few subjects had low ABIs [18-21]. Thus, we aimed to evaluate the concordance between automated oscillometric measurement of ABI and the standard measurement by eco-Doppler in diabetic Chinese patients with or without diabetic foot.

\section{Methods and Patients}

2.1. Study Population. 328 consecutive patients with diabetes who were admitted to the Diabetic Foot Care Center, Department of Endocrinology and Metabolism, West China Hospital, from May 2013 to June 2014 were recruited. Participants were excluded if they reported any history of previous bypass surgery or angioplasty, any major amputations on the lower or upper limbs, marked edema of one or both feet, and atrial fibrillation. Finally, 230 consecutive patients with diabetes $(n=459$ limbs, mean age $61.28 \pm 14.50$ years, 126 men, 82 diabetic foot) were included our study. Figure 1 presented the flow chart of the study. The study protocol, patients' informed consent forms, and other study related documents were reviewed and approved by the ethics committee of the
West China Hospital, and all participants provided written informed consent prior to participating in the study.

2.2. Determination of $A B I$. All measurements were obtained after the patients had rested for ten min in the supine decubitus position in a room with a comfortable temperature $\left(24 \pm 1^{\circ} \mathrm{C}\right)$, without smoking, heavy exercise, and drinking alcohol or caffeinated beverages for at least $2 \mathrm{~h}$ before the examination. The ABI was determined by the automatic method using a validated oscillometric device (OMRON BP-203RPEIII) that allows simultaneous armleg BP measurements and using a validated and calibrated sphygmomanometer and a two-way Doppler with an $8 \mathrm{MHz}$ probe (Bidop Es-100V3. HADECO) by the same specially trained nurse with 10 years of experience in ABI measurement. Doppler-ABI measurement was invariably performed first because of the higher degree of subjectivity. For oscillometric ABI, they used appropriate cuff sizes on the arms and ankles, thus avoiding a potential bias by variations of blood pressure. Ankle pressures were measured over the dorsalis and posterior tibial arteries. Limbs were measured twice at the same time and the time interval was 10 seconds. ABI was calculated by dividing the highest value obtained at each ankle by the highest of the arm values. The ABI of both the left and right legs was recorded, and for the definition of PAD, the lower value between the two was considered [22].

2.3. Statistical Analysis. The results were analyzed by diagnostic test analysis method. Continuous variables are summarized as mean \pm standard deviation (SD) when normally distributed and as median (interquartile range) when asymmetrically distributed and categorical variables as percentage. ABI measurements were compared using a 
Table 1: Patient demographics and clinical characteristics.

\begin{tabular}{|c|c|}
\hline Variable & Value \\
\hline Male (\%) & $126 / 230(54.78 \%)$ \\
\hline Age (years) & $61.28 \pm 14.50$ \\
\hline Duration of diabetes (years) & $8.97 \pm 6.77$ \\
\hline BMI $\left(\mathrm{kg} / \mathrm{m}^{2}\right)$ & $23.50 \pm 3.97$ \\
\hline HbAlc (\%) & $8.83 \pm 2.54$ \\
\hline $\mathrm{FBG}(\mathrm{mol} / \mathrm{L})$ & $9.35 \pm 4.02$ \\
\hline $\mathrm{CHOL}(\mathrm{mol} / \mathrm{L})$ & $4.41 \pm 1.30$ \\
\hline $\mathrm{TG}(\mathrm{mol} / \mathrm{L})$ & $1.88 \pm 1.70$ \\
\hline HDL-C (mol/L) & $1.20 \pm 0.37$ \\
\hline LDL-C (mol/L) & $2.54 \pm 1.08$ \\
\hline Creatinine $(\mathrm{mol} / \mathrm{L})$ & $88.31 \pm 50.12$ \\
\hline Intermittent claudication & $45 / 230(19.57 \%)$ \\
\hline Rest pain & $32 / 230(13.91 \%)$ \\
\hline Coronary heart disease & $98 / 230(42.61 \%)$ \\
\hline Cerebrovascular disease & $50 / 230(21.74 \%)$ \\
\hline Retinopathy & $103 / 230(44.78 \%)$ \\
\hline Neuropathy & $158 / 230(68.70 \%)$ \\
\hline Hypertension & $154 / 230(66.96 \%)$ \\
\hline Hypercholesterolemia & $16 / 320(5.00 \%)$ \\
\hline Hypertriglyceridemia & $52 / 320(22.61 \%)$ \\
\hline Peripheral arterial disease & $56 / 230(24.35 \%)$ \\
\hline Diabetic foot & $82 / 230(35.65 \%)$ \\
\hline Wagner grade 1 & $3 / 82(3.66 \%)$ \\
\hline Wagner grade 2 & $12 / 82(14.63 \%)$ \\
\hline Wagner grade 3 & $40 / 82(48.78 \%)$ \\
\hline Wagner grade 4 & $25 / 82(30.49 \%)$ \\
\hline Wagner grade 5 & $2 / 82(2.44 \%)$ \\
\hline
\end{tabular}

BMI: body mass index; FBG: fasting blood glucose; CHOL: cholesterol; TG: triglyceride; HDL-C: high density lipoprotein cholesterol; LDL-C: low density lipoprotein cholesterol.

paired Student's $t$-test. The intermethod concordance between both techniques was assessed by kappa coefficient and the Bland-Altman method was determined to analyze the agreement. Diagnostic accuracy was assessed via sensitivity, specificity, accuracy, positive likelihood ratio (+LR), negative likelihood ratio ( $-\mathrm{LR}$ ), with $\mathrm{ABI}$ readings dichotomized $(\mathrm{ABI} \leq 0.9)$, and receiver operating characteristic (ROC) curve analysis using both univariable and multivariable logistic regressions. Conventionally, Cohen's kappa statistic below 0.2 is considered poor agreement, $0.21-0.4$ fair, 0.41-0.6 moderate, $0.61-0.8$ strong, and over 0.8 near complete agreement [23]. $p<0.05$ was accepted as indicating statistical significance. The statistical analysis was carried out using the SPSS statistics package, version 16.0 (SPSS Inc., Chicago, IL, USA) and MedCalc 15.8 software.

\section{Results}

3.1. Patient Characteristics. Patient characteristics are shown in Table 1.

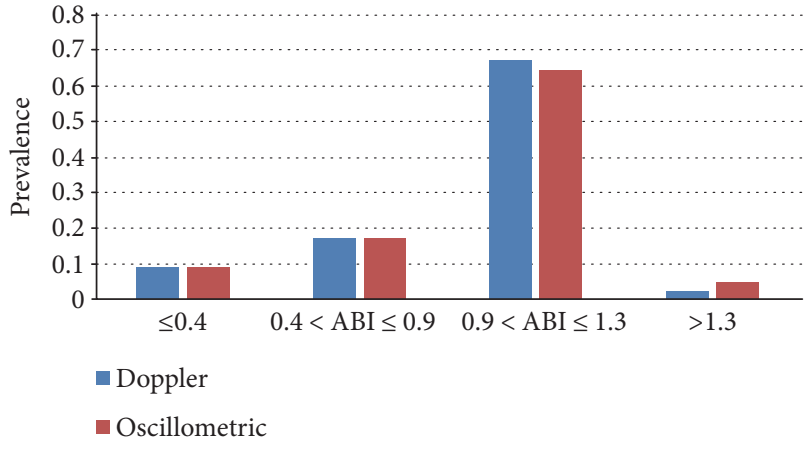

Figure 2: Prevalence across the categories of Doppler and oscillometric ABI values.

3.2. Comparison of the Two Methods. ABI values measured by eco-Doppler showed $1.003 \pm 0.286(0.210-1.390)$ on the right limb and $0.990 \pm 0.287(0.000-1.000)$ on the left limb, while the automated oscillometric measurement showed 1.002 $\pm 0.332(0.000-1.900)$ on the right and $0.993 \pm 0.319$ $(0.000-1.390)$ on the left. The difference of the oscillometric $\mathrm{ABIs}$ and the Doppler ABIs was not significant on the right $(95 \% \mathrm{CI}=-0.0203-0.0185, p=0.930)$ and left legs $(95 \%$ $\mathrm{CI}=-0.0146-0.0209, p=0.727)$. Pathological ABI by ecoDoppler was detected in 67 (29.13\%) subjects, including 43 subjects with abnormal $\mathrm{ABI}$ at two limbs and 24 subjects at one limb and in $66(28.70 \%)$ subjects using the automated oscillometric measurement including 43 subjects at two limbs and 23 subjects at one limb. The prevalence across the categories of Doppler and oscillometric ABI values are shown in Figure 2; no significant differences were observed for $\mathrm{ABI} \leq 0.4,0.4<\mathrm{ABI} \leq 0.9,0.9<\mathrm{ABI} \leq 1.3$, and $\mathrm{ABI}>1.3\left(x^{2}=2.703, p=0.259\right)$. Compared to $\mathrm{ABI}$ obtained by eco-Doppler, the automated oscillometric measurement produced a false positive result in $6(8.96 \%)$ patients and a false negative result in $6(3.82 \%)$ patients.

3.3. The Agreements between Doppler and Automatic Methods. The Bland-Altman plots of the difference comparison assessing the agreement of the two methods for all 230 patients are shown in Figure 3; the paired mean (95\% confidence interval (CI)) difference between two measuring devices according the Altman-Bland method was -0.0009 (95\% CI $=-0.2993$ to $0.2976, p<0.0005)$ in the right limbs and $0.0031(95 \% \mathrm{CI}=-0.2692$ to $0.2755, p<0.0001)$ in the left limbs. The value-to-value comparison showed good agreement between the two methods.

3.4. Sensitivity and Specificity. Regarding the eco-Doppler measurement as the gold standard (defined $\mathrm{ABI} \leq 0.9$ as PAD), there were 173 true negatives, 50 true positives, 4 false negatives, and 3 false positives in the right legs, and 13 patients with an automatic index that was not measurable were classified correctly as true positives. There were 171 true negatives, 53 true positives, 2 false negatives, and 3 false positives in the left legs, and there were 11 patients with an automatic index that was not measurable. While in the analysis in terms of patients rather than limbs in the 230 patients with determination of ABI by both methods, there 


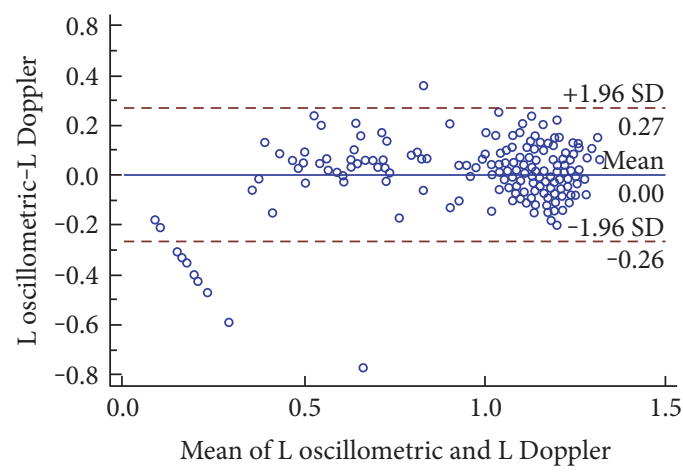

(a)

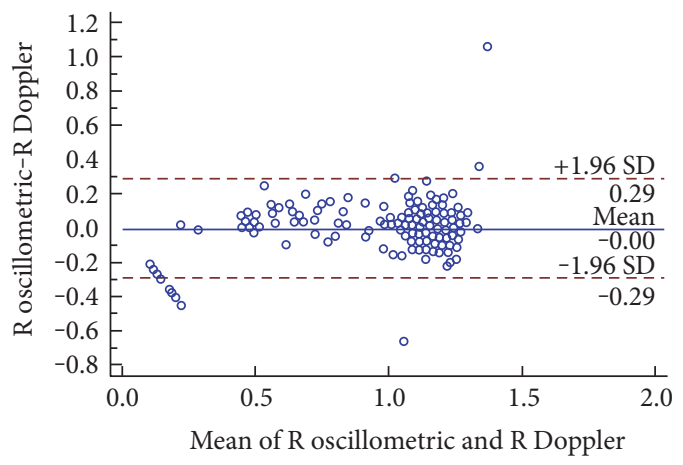

(b)

FIgUre 3: The Bland-Altman plots for the ABI by oscillometric and Doppler devices.

TABLE 2: Accuracy of the oscillometric method compared with that of the gold standard.

\begin{tabular}{|c|c|c|c|c|c|c|c|}
\hline & Accuracy & Sensitivity & Specificity & $+\mathrm{LR}$ & $-\mathrm{LR}$ & $p$ & $\overline{\text { Kappa }}$ \\
\hline Right limb & $95.22 \%$ & $94.34 \%$ & $95.48 \%$ & 20.87 & 0.059 & 0.000 & 0.869 \\
\hline Left limb & $96.94 \%$ & $96.43 \%$ & $97.11 \%$ & 33.36 & 0.036 & 0.000 & 0.919 \\
\hline Combined analysis & $97.37 \%$ & $94.50 \%$ & $98.29 \%$ & 55.12 & 0.056 & 0.001 & 0.928 \\
\hline
\end{tabular}



(a)

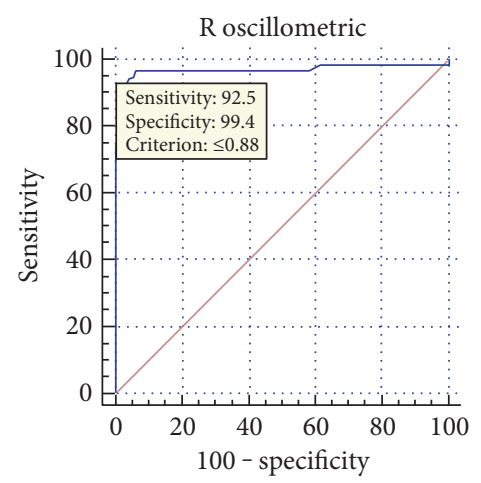

(b)

FIGURE 4: The area under the receiver operating characteristic curve for ABI measured by oscillometric analysis compared with that measured by Doppler analysis.

were 157 true negatives, 61 true positives, 6 false negatives, and 6 false positives, and there were 16 patients with an automatic index that was not measurable. Sensitivity, specificity, positive likelihood ratio, negative likelihood ratio, accuracy, and kappa values of the oscillometric method are shown in Table 2. The area under the receiver operating characteristic (ROC) curve was 0.993 (95\% CI $=0.972$ to 1.000$)$ on the left limbs and 0.967 (95\% CI $=0.935$ to 0.986$)$ on the right limbs (Figure 4); in the combined analysis, the area under the ROC was 0.981 (95\% CI $=0.964$ to 0.991$)$.

3.5. Comparison of Time Consumption. The mean time consumption for measurements with the automatic device and the handheld Doppler device was $8.60 \pm 1.38$ (ranges: 7.00-14.00) and 16.98 \pm 3.20 (ranges: 10.00-30.00) minutes per patient, respectively. Compared to the handheld Doppler, the process of performing the automated oscillometric device consumed significantly less time $(p<0.001)$.

\section{Discussion}

Our previous studies indicated that PAD existed in "three high" (high prevalence, high morbidity, and high mortality) and "three low" (low diagnosis, low treatment, and low awareness) conditions [24]. PAD was a risk factor of diabetic foot and one of the independent risk factors of diabetic foot 
amputation $[25,26]$. Thus, early detection of PAD is necessary to prevent diabetic foot and amputation. The validity and reliability of automated oscillometric ABI values for diagnosis of PAD is controversial [14-21, 23]. Although the Doppler-derived $\mathrm{ABI}$ was the gold standard to $\mathrm{ABI}$, oscillometric-ABI measurement is simple and convenient with low cost for PAD screening [21, 27]. However, few studies have validated the concordance between oscillometric $\mathrm{ABI}$ and Doppler ABI in China.

In this study, we found that the automated oscillometricABI-measuring results was highly consistent with those by eco-Doppler methods and the former is less time consuming. The previous studies showed the correlation between the two methods ranging from 0.53 to 0.86 [19-23]. This study showed that the kappa value was 0.869 and 0.919 for the right and left legs, respectively. Using the Doppler-derived ABI as the gold standard and that the cutoff value was 0.9 , the sensitivity and specificity of the oscillometric method are $94.50 \%$ and 98.29\%, respectively, with the receiver operating characteristic (ROC) curve being 0.992. Most recently, Herráiz-Adillo et al. [28] published a similar study (43\% diabetics, $n=151$ legs), which showed a sensitivity of $66.7 \%$, a specificity of $96.8 \%$, and an accuracy of $91.39 \%$, with a kappa coefficient of 0.684 and $\mathrm{AUC}=0.944$ (95\% CI $=0.905$ to 0.983 ). Furthermore, when they were considering calcified legs as PAD equivalents ( $n=180$ legs), the sensitivity, specificity, and accuracy were $78.2 \%, 96 \%$, and $90.56 \%$, respectively, with a kappa coefficient of 0.645 and $\mathrm{AUC}=0.914$ (95\% CI $=0.872$ to 0.955$)$. The differences between the study of Herráiz-Adillo et al. and our study maybe due to the different selected subjects and the detection equipment (OMRON M3 versus OMRON BP203RPEIII). Especially, high sensitivity (90\%) and specificity (98\%) of oscillometric test for stenosis of $\geq 50 \%$ in the arteries of the lower limbs were found in this and other studies [29]. However, some studies [29,30] showed that oscillometry overestimated ankle pressure and the ABI result was unreliable. Actually, ABI values were comparatively lower while the ABI values $\leq 0.4$ compared with eco-Doppler. There are 23 cases which $\mathrm{ABI}<0.4$, while 16 of them cannot be detected by oscillometric measurement. Therefore, if the oscillometric device cannot detect specific ABI data, it indicated that the lower limb artery lesion was severe with $\mathrm{ABI}<0.4$. Further examinations such as CTA, MRA, and angiography were needed to evaluate and treatment of PAD must be initiated.

The time needed for Doppler ABI was longer than that for oscillometric-ABI methods (16.98 \pm 3.20 (10.00-30.00) min versus $8.60 \pm 1.38(7.00-14.00) \mathrm{min})$. It may be due to the necessity of additional steps with Doppler, such as pulse palpation, the application of gel, signal viewing, and operational levels. The different results between the two methods were acceptable. The eco-Doppler method was affected by the operator and the intrinsic bias existed during measurement. And the automated oscillometric-ABI value was not influenced by the operator and the results were more reliable.

Most published researches were based on nondiabetic population and suggested that an automated oscillometric $\mathrm{ABI}$ measurement is a reliable and practical alternative to the conventional Doppler measurement for the detection of PAD. Our objectives of the study were involved diabetic patients to validate. Our study was a single-center study and a sample size was not enough; further studies need to be performed.

In conclusion, our finding suggested that $\mathrm{ABI}$ values measured by automated oscillometric method were highly consistent with those by eco-Doppler method. The former was convenient and less time consuming, which can be widely used in the primary care center without special training.

\section{Disclosure}

The funders had no direct role in the study design; in the collection, analysis, and interpretation of data; in the writing of the report; and in the decision to submit the article for publication. The researchers were independent of the researchers from the funders. Xingwu Ran is the study guarantor and had full access to all the data in the study and takes responsibility for the integrity of the data and the accuracy of the data analysis and is responsible for critical revision and final approval of the version to be published.

\section{Conflicts of Interest}

There are no ethical/legal conflicts involved in the article. There are no conflicts of interest, including specific financial interests and relationships and affiliations relevant to the subject of their manuscript.

\section{Authors' Contributions}

Jing Ma and Min Liu contributed equally to this study. All the authors read and approved the final manuscript and contributed to the design, collection and analysis of the data, and drafting of the work.

\section{Acknowledgments}

This study is supported by the National Natural Science Foundation of China (81471043) and Science and Technology Bureau of Sichuan Province (2015sz0228-4; 2015HM02-00085-SF). The authors thank all patients, practice nurses, and investigators for their contributions to this study.

\section{References}

[1] A. Dinesh Shah, C. Langenberg, E. Rapsomaniki et al., "Type 2 diabetes and incidence of a wide range of cardiovascular diseases: a cohort study in 1.9 million people," Lancet (London, England), vol. 385, Supplement 1, p. S86, 2015.

[2] H. Guan, Y. J. Li, Z. R. Xu et al., "Prevalence and risk factors of peripheral arterial disease in diabetic patients over 50 years old in China," Chinese Medical Sciences Journal, vol. 22, no. 2, pp. 83-88, 2007.

[3] C. Wang, T. T. Yu, Y. Wang et al., "Survey of peripheral arterial disease and analysis of its risk factors in hospitalized diabetic patients," Chinese Journal of Diabetes, vol. 15, no. 11, pp. 643-646, 2007.

[4] Y. Wang, Q. Mou, D. Zhao et al., "Predictive value of anklebrachial index and blood glucose on the outcomes of six-year 
all-cause mortality and cardiovascular mortality in a Chinese population of type 2 diabetes patients," International Angiology, vol. 31, no. 6, pp. 586-594, 2012.

[5] H. Yokoyama, H. Sone, J. Honjo et al., "Relationship between a low ankle brachial index and all-cause death and cardiovascular events in subjects with and without diabetes," Journal of Atherosclerosis and Thrombosis., vol. 21, no. 6, pp. 574-581, 2014.

[6] M. M. McDermott, L. Fried, E. Simonsick, S. Ling, and J. M. Guralnik, "Asymptomatic peripheral arterial disease is independently associated with impaired lower extremity functioning: the women's health and aging study," Circulation, vol. 101, no. 9, pp. 1007-1012, 2000.

[7] T. Mueller, F. Hinterreiter, W. Poelz, M. Haltmayer, and B. Dieplinger, "Mortality rates at 10 years are higher in diabetic than in non-diabetic patients with chronic lower extremity peripheral arterial disease," Vascular Medicine, vol. 21, no. 5, pp. 445-452, 2016.

[8] D. Mukherjee and L. Cho, "Peripheral arterial disease: considerations in risks, diagnosis, and treatment," Journal of the National Medical Association, vol. 101, no. 10, pp. 999-1008, 2009.

[9] B. S. Ferket, S. Spronk, E. B. Colkesen, and M. G. Hunink, "Systematic review of guidelines on peripheral artery disease screening," The American Journal of Medicine, vol. 125, no. 2, pp. 198-208, 2012, e3.

[10] European Stroke O, M. Tendera, V. Aboyans et al., "ESC guidelines on the diagnosis and treatment of peripheral artery diseases: document covering atherosclerotic disease of extracranial carotid and vertebral, mesenteric, renal, upper and lower extremity arteries: the task force on the diagnosis and treatment of peripheral artery diseases of the European Society of Cardiology (ESC)," European Heart Journal, vol. 32, no. 22, pp. 2851-2906, 2011.

[11] E. R. Mohler III, D. Treat-Jacobson, M. P. Reilly et al., "Utility and barriers to performance of the ankle-brachial index in primary care practice," Vascular Medicine, vol. 9, no. 4, pp. 253-260, 2004.

[12] C. Clairotte, S. Retout, L. Potier, R. Roussel, and B. Escoubet, "Automated ankle-brachial pressure index measurement by clinical staff for peripheral arterial disease diagnosis in nondiabetic and diabetic patients," Diabetes Care, vol. 32, no. 7, pp. 1231-1236, 2009.

[13] F. Crawford, K. Welch, A. Andras, and F. M. Chappell, “Ankle brachial index for the diagnosis of lower limb peripheral arterial disease," The Cochrane Database of Systematic Reviews, vol. 9, Article ID CD010680, 2016.

[14] M. Premanath and M. Raghunath, "Ankle-brachial index by oscillometry: a very useful method to assess peripheral arterial disease in diabetes," International Journal of Diabetes in Developing Countries, vol. 30, no. 2, pp. 97-101, 2010.

[15] E. MacDonald, P. Froggatt, G. Lawrence, and S. Blair, “Are automated blood pressure monitors accurate enough to calculate the ankle brachial pressure index?" Journal of Clinical Monitoring and Computing, vol. 22, no. 5, pp. 381-384, 2008.

[16] A. Kollias, A. Xilomenos, A. Protogerou, E. Dimakakos, and G. S. Stergiou, "Automated determination of the anklebrachial index using an oscillometric blood pressure monitor: validation vs. Doppler measurement and cardiovascular risk factor profile," Hypertension Research, vol. 34, no. 7, pp. 825-830, 2011.
[17] G. C. Rodriguez-Roca, A. Villarin-Castro, J. Carrasco-Flores et al., "Concordance between automated oscillometric measurement of ankle-brachial index and traditional measurement by eco-Doppler in patients without peripheral artery disease," Blood Pressure, vol. 23, no. 5, pp. 270-275, 2014.

[18] E. Vinyoles, E. Pujol, J. Casermeiro, C. de Prado, and S. J. V. Salido, "Ankle-brachial index to detect peripheral arterial disease concordance and validation study between Doppler and an oscillometric device," Medicina Clinica, vol. 128, no. 3, pp. 92-94, 2007.

[19] R. Fores, M. T. Alzamora, G. Pera, P. Toran, M. Urrea, and A. Heras, "Concordance between 3 methods of measurement the ankle-brachial index to diagnose peripheral artery disease," Medicina Clinica, vol. 143, no. 8, pp. 335-340, 2014.

[20] M. Korno, N. Eldrup, and H. Sillesen, "Comparison of anklebrachial index measured by an automated oscillometric apparatus with that by standard Doppler technique in vascular patients," European Journal of Vascular and Endovascular Surgery, vol. 38, no. 5, pp. 610-615, 2009.

[21] J. F. Hamel, D. Foucaud, and S. Fanello, "Comparison of the automated oscillometric method with the gold standard Doppler ultrasound method to access the ankle-brachial pressure index," Angiology, vol. 61, no. 5, pp. 487-491, 2010.

[22] Subcommittee WCPW, "Ankle brachial index: quick reference guide for clinicians," Journal of Wound, Ostomy, and Continence Nursing, vol. 39, no. 2 Supplement, pp. S21-S29, 2012.

[23] I. Takahashi, K. Furukawa, W. Ohishi, T. Takahashi, M. Matsumoto, and S. Fujiwara, "Comparison between oscillometricand Doppler-ABI in elderly individuals," Vascular Health and Risk Management., vol. 9, no. 9, pp. 89-94, 2013.

[24] X. W. Ran, "Diabetic peripheral arterial disease: a overlooked problem by the clinician," Zhonghua Yi Xue Za Zhi, vol. 92, no. 4, pp. 217-218, 2012.

[25] Y. F. Fei, C. Wang, D. W. Chen et al., "Incidence and risk factors of amputation among inpatients with diabetic foot," Zhonghua Yi Xue Za Zhi, vol. 92, no. 24, pp. 1686-1689, 2012.

[26] Y. H. Li, L. P. He, C. Wang, G. J. Liu, D. W. Chen, and L. H. Chen, "Analysis of risk factors of diabetic foot," Chinese Journal of Diabetes Mellitus, vol. 4, no. 3, pp. 155-158, 2012.

[27] S. M. Grenon, J. Gagnon, and Y. Hsiang, "Video in clinical medicine. Ankle-brachial index for assessment of peripheral arterial disease," The New England Journal of Medicine, vol. 361, no. 19, p. e40, 2009.

[28] A. Herráiz-Adillo, V. Martinez-Vizcaino, I. Cavero-Redondo, C. Alvarez-Bueno, M. Garrido-Miguel, and B. NotarioPacheco, "Diagnostic accuracy study of an oscillometric ankle-brachial index in peripheral arterial disease: the influence of oscillometric errors and calcified legs," PloS One, vol. 11, no. 11, Article ID e0167408, 2016.

[29] K. Ouriel, A. E. McDonnell, C. E. Metz, and C. K. Zarins, "Critical evaluation of stress testing in the diagnosis of peripheral vascular disease," Surgery, vol. 91, no. 6, pp. 686-693, 1982.

[30] Y. Nukumizu, M. Matsushita, T. Sakurai, M. Kobayashi, N. Nishikimi, and K. Komori, "Comparison of Doppler and oscillometric ankle blood pressure measurement in patients with angiographically documented lower extremity arterial occlusive disease," Angiology, vol. 58, no. 3, pp. 303-308, 2007. 


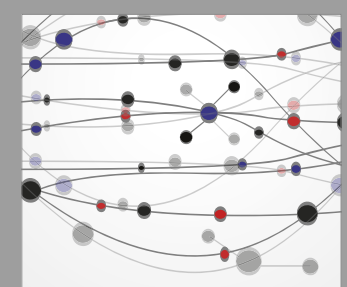

The Scientific World Journal
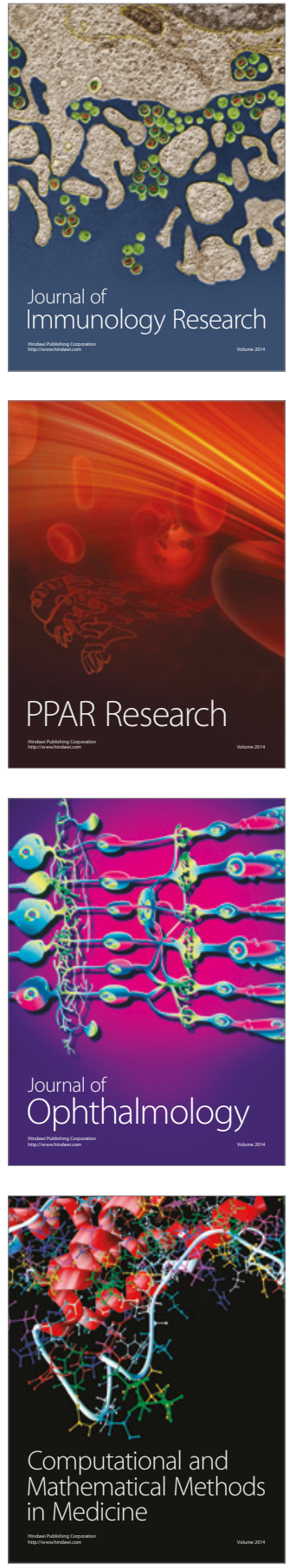

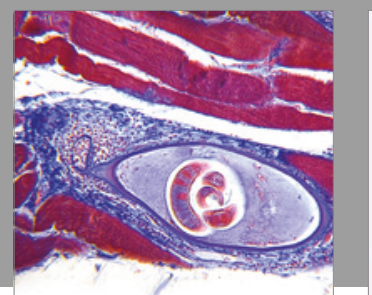

Gastroenterology Research and Practice
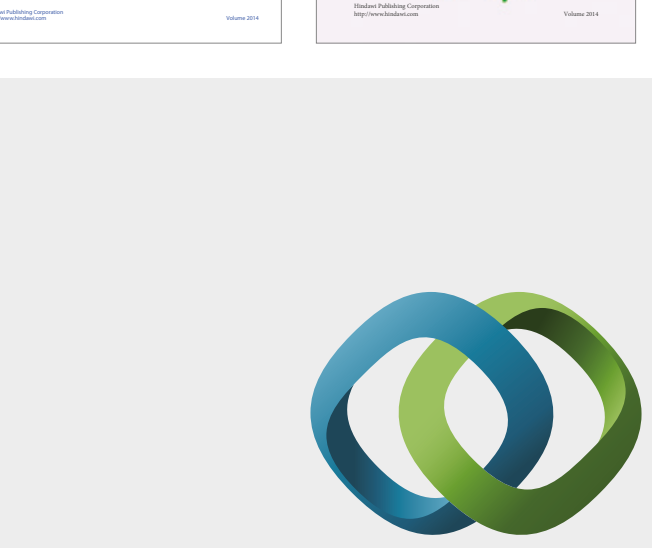

\section{Hindawi}

Submit your manuscripts at

https://www.hindawi.com
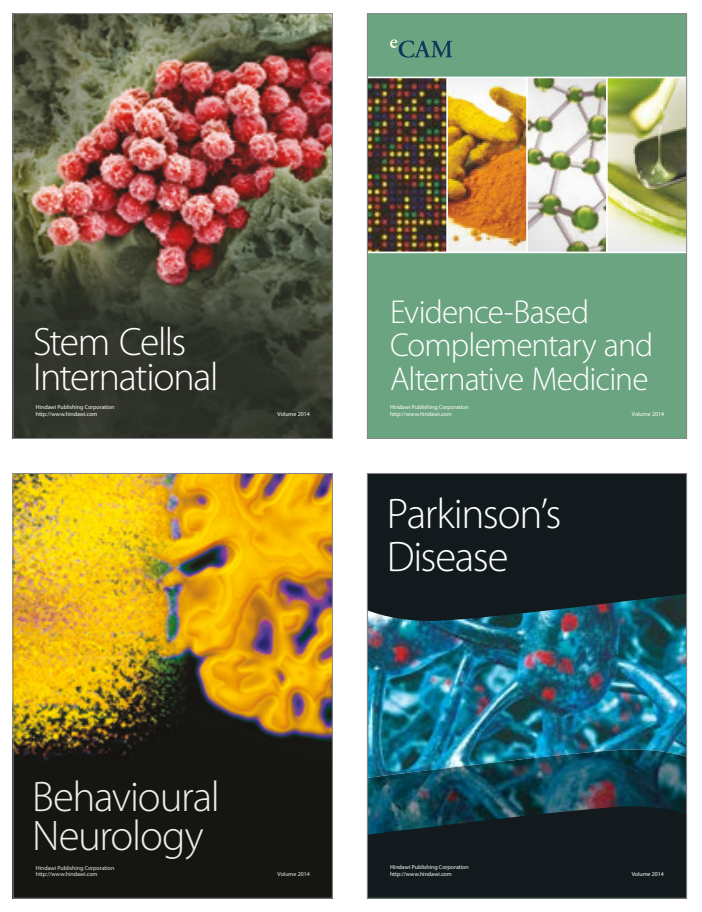
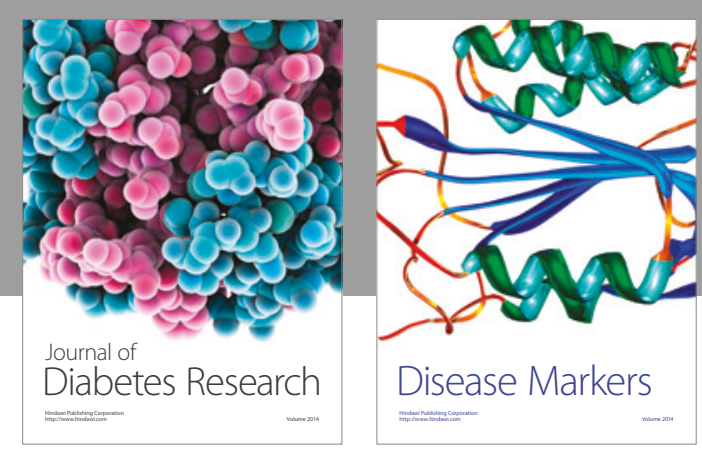

Disease Markers
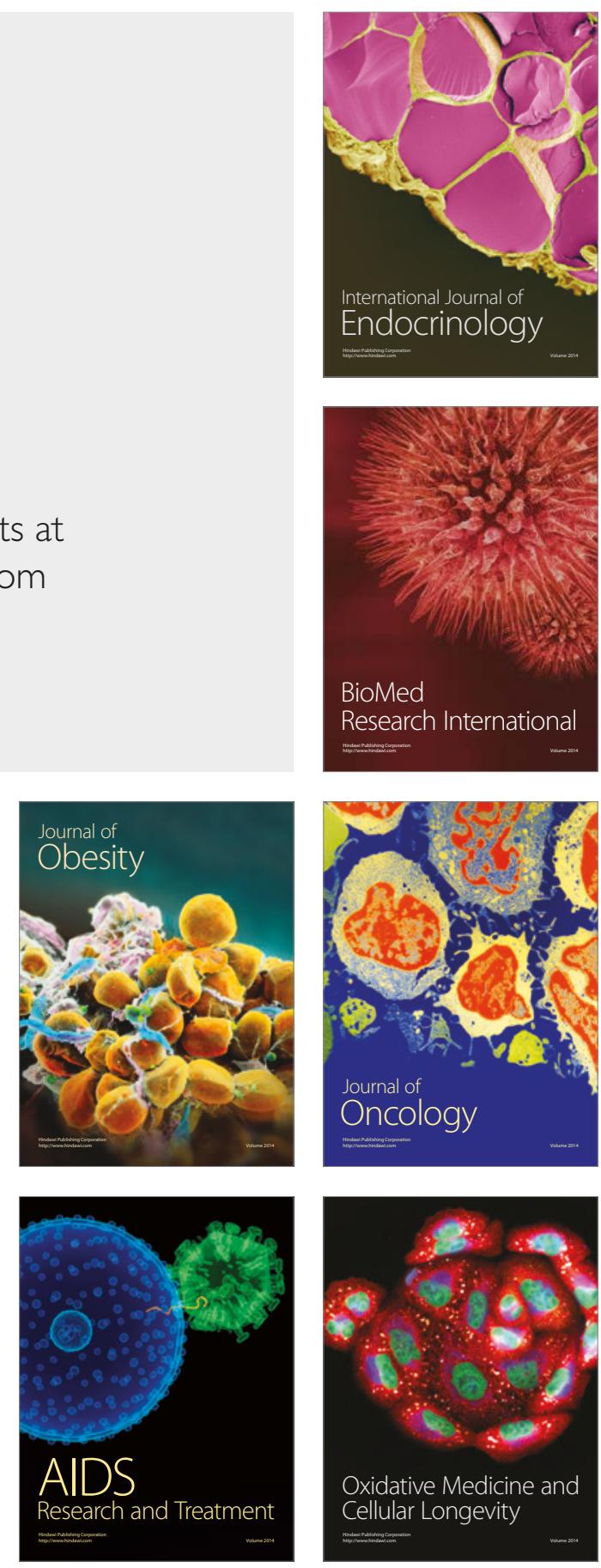